\title{
Seasonal to Decadal Temperature Variations in the Faroe-Shetland Inflow Waters
}

\author{
Hjalmar Hátún ${ }^{1}$, Anne Britt Sandø², Helge Drange $e^{2,3,4} \&$ Mats Bentsen²,4
}

\begin{abstract}
A 53 years hind-cast simulation with a regional version of the Nansen Center version of the Miami Isopycnic Coordinate Ocean Model (MICOM) has been conducted to explore the nature of the observed seasonal to inter-annual variations in the temperature of the pole-ward flowing Atlantic Water (AW) crossing the IcelandScotland Ridge (ISR). It is found that the simulated long-term temperature variations closely resemble observations south of the ridge (Rockall Trough), north of the ridge (Svinøy section) and between (Faroe Shetland Channel, FSC). The simulated temperature on the Faroe Shelf is also compared to daily temperature observations from Mykines, revealing realistic long-term temperature variations, seasonal variations and a realistic seasonal modulation. The simulated time series in the FSC indicates that the phase and amplitude of the annual temperature cycle of the AW have varied by almost one month and $0.15^{\circ} \mathrm{C}$ between the 1960 s and 2001, illustrating the difficulty in unambiguously removing the seasonal cycle from the, sparsely sampled, time series. It is argued that the simulated time series can be used to complement the observed time series in periods with sparse sampling. Specifically, the observation-based cold anomaly in the late 1960s and the warming in the early 1980s should be treated with caution. Finally, the analysis indicates that it is not advisable to survey the hydrographic section less than four times a year if reliable decadal scale temperature variations are of interest.
\end{abstract}

\section{INTRODUCTION}

The southeastern part of the Nordic Seas is among the longest-time [Helland-Hansen and Nansen, 1909] and most frequently [Hansen and Østerhus, 2000] sampled regions of the World Ocean. It is also, together with the Barents Sea, a region of high biological production [Anderson et al., 2000; Sakshaug et al., 1994]. Mounting evidence shows that the biological production is closely related to the actual state of the marine climate in the region, particularly to the flow of warm, saline and nutrient-rich AW across the Greenland-Scotland Ridge (GSR), [Beaugrand and Reid, 2003]. Furthermore, the inflow of AW keeps the Barents Sea and the waters south of Svalbard ice free throughout the year, and is consequently of key importance for the local climate in western Scandinavia and north-western Russia. The salt transported into the Nordic Seas is of fundamental role for the formation of intermediate waters in the region, and it is a key component in the formation of abyss water that occasionally takes place in the Greenland Sea. The thermodynamic transformation of the AW that takes place north of GSR is thus also linked to the Atlantic thermohaline circulation [Dickson and Brown, 1994].

The flux of AW entering the Nordic Seas between Iceland and the Faroes, and between the Faroes and Scotland, is about equally distributed and amounts to about $3.5 \mathrm{~Sv}\left(1 \mathrm{~Sv}=10^{6}\right.$ $\mathrm{m}^{3} \mathrm{~s}^{-1}$ ) each [Hansen et al., 2003; Turrell et al., 2003]. A third

1 Faroese Fisheries Laboratory, Tórshavn, Faroe Islands 2 Nansen Environmental and Remote Sensing Center, Bergen, Norway

3 Geophysical Department, University of Bergen, Bergen, Norway

4 Bjerknes Centre for Climate Research, Bergen, Norway branch of AW enters the Nordic Seas through the Denmark Strait. The latter is rather weak with an inflow of less than 1 Sv, [Kristmannsson, 2001]. The hydrography of the AW entering the Nordic Seas between the Faroes and Scotland has been routinely observed by the Faroese Fisheries Laboratory and the Marine Laboratory in Aberdeen throughout most of the 20th century. This is illustrated by an annual average of 3.6 hydrography cruises during the second half of the 20th century, yielding a unique source of information about the seasonal to decadal variability of the properties of the inflowing AW.

The Faroes-Scotland time series have been used in a series of studies, including tracing hydrographic anomalies propagating through the Nordic Seas [Belkin et al., 1998; Furevik, 2001]. Although frequently sampled, there are periods with only one or two observations per year and with a highly variable seasonal cycle in the FSC [Hansen et al., 1994], this can lead to difficulties in uniquely identifying the seasonal cycle and the inter-annual temperature anomalies in the series. The consequence of this can be that spurious temperature and salinity anomalies are deduced from the data material [Reverdin et al., 1994]. Here we present a hind-cast simulation with a regional version of the Miami Isopycnic Coordinate Ocean Model (MICOM) [Bleck et al., 1992] to 1) evaluate one aspect of the model performance, to 2) assess whether the observed time series can be complimented for the period 1948 to 2001, and to 3) provide guidance for the future sampling strategy of the Faroes-Scotland transect.

The paper starts with a description of the applied model system (Section 2). Then simulated and observed long-term 
temperature variations from three standard hydrographical sections crossing current branches of the northward flowing AW are analysed (Section 3). In Section 4, the daily temperature record from Mykines is analysed and used as background for a seasonality and aliasing analysis of the observed and simulated temperature time series from the FSC. In Section 5, some possible applications of a general circulation model (GCM) are illustrated followed by a discussion and some conclusions in Section 6.

\section{MODEL DESCRIPTION}

The model system adopted in this study consists of the global Nansen Center version of MICOM [Bentsen et al., 2004; Furevik et al., 2002; Nilsen et al., 2003], and a regional version of the same model system covering the Atlantic Ocean between $30^{\circ} \mathrm{N}-78^{\circ} \mathrm{N}$. The global version of the model used in this study has a horizontal resolution of about $40 \mathrm{~km}$ over most of the North Atlantic Ocean. The grid configuration of the regional model is identical to the global model but with doubled horizontal resolution, e.g. with about $20 \mathrm{~km}$ grid spacing in the region of the ISR.

The nesting approach applies a boundary relaxation scheme towards the outer (i.e., global) solution. This results in a socalled one way nesting where the boundary conditions of the regional model are relaxed towards the output from the global model. For the slowly varying baroclinic velocity, temperature, salinity and layer interface variables, this is a fully appropriate way to include the boundary conditions. For the barotropic variables, the relaxation approach requires careful tuning to avoid reflection of waves at the open boundaries. It is possible to compute the barotropic boundary conditions exactly while taking into consideration both the waves propagating into and out of the regional model (see ftp:// micom.rsmas.miami.edu/bleck/open_bdy.tex for details). The regional model reads the global fields once a week and interpolates in time to specify the relaxation boundary conditions at each time step.

In the vertical, both model versions have 26 layers of which the uppermost mixed layer has temporal and spatial varying density, and the 25 layers below have constant density. Daily mean NCAR/NCEP re-analyses [Kistler et al., 2001] fresh water, heat and momentum fluxes are used to force the system by applying the scheme of Bentsen and Drange [2000]. If the model sea surface state is equal to the assumed sea surface state with the NCEP/NCAR reanalysis data, the turbulent fluxes of momentum and heat are estimated by the atmospheric model, which provides the re-analysis data. This model uses bulk expressions to estimate the turbulent fluxes with the coefficients determined by [Miyakoda and Sirutis, 1986]. If the sea surface state differs in the ocean model and re-analysis data, the fluxes will be modified.

In the regional model, the mixed layer temperature and salinity fields are linearly relaxed towards the monthly mean climatological values of [Levitus et al., 1994] and [Levitus and Boyer, 1994], respectively. The e-folding relaxation time scale is set to 30 days for a $50 \mathrm{~m}$ thick mixed layer, and is reduced linearly with the mixed layer exceeding $50 \mathrm{~m}$.

If the relaxation to the climatology is too strong, the model will not be able to reproduce the observed amplitude and phase shifts during the modelling period due to the fixed seasonal properties of the climatology. The applied relaxation is rather weak, allowing for seasonal to inter-annual variations in the simulated mixed layer properties as will be demonstrated below.

\subsection{General Remarks on the Applied Model System}

The applied horizontal grid resolution of about $20 \mathrm{~km}$ implies that the model is far from eddy-resolving in the region of interest, but sufficient to pick up the main topographic steering-effect on the currents, and similar to the distance between current meters and the standard hydrographic stations along the standard measurement sections in the region. The model grid will seldom coincide exactly with the actual positions of standard hydrographical stations, but this does not affect the results crucially, at least not when the mean value over a certain region is considered.

The simulated hydrography in the ISR-region is, on average, too fresh by about 0.1 psu [Furevik et al., 2002] and too cold by $0.44^{\circ} \mathrm{C}$ (see below). These deviations may, however, not influence the simulated seasonal to decadal-scale variability in salinity and temperature. Furthermore, simulated volume transports over the ISR, calculated as the net amount of water passing the openings from surface to bottom between 1948-2001, have been compared to transport values from the literature [Nilsen et al., 2003]. These are found to be reasonable although the branch north and northwest of the Faroes is too weak, possibly as a result of the non-eddy-resolving model resolution.

\section{SIMULATED LONG-TERM HYDROGRAPHY IN THE FSC}

High quality CTD-data are available from the MunkenFair Isle section between the Faroes and Scotland (Fig. 1) since 1994. The salinity, horizontally integrated at 50 meters depths from the Shetland Shelf half way towards the Faroes, is com-

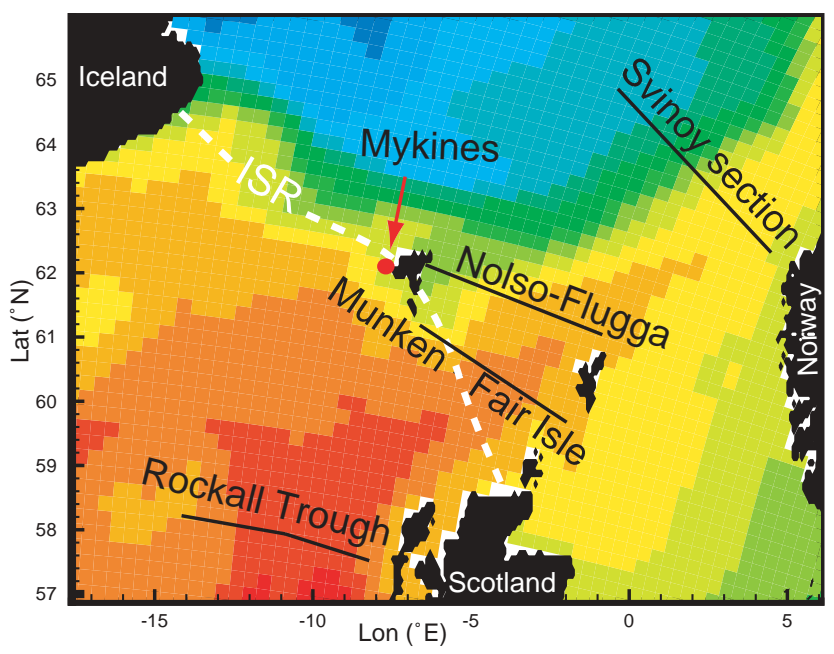

Figure 1. The temperatures $\mathrm{T}\left(\mathrm{T}<3{ }^{\circ} \mathrm{C}\right.$ for the bluish colors; $\mathrm{T}>9^{\circ} \mathrm{C}$ for the pure red color) averaged over the mixed layer in the region of the ISR for the years 1996-2001. The standard hydrographical sections used in the analyses are indicated with the black lines and the coastal station at Mykines is shown with the red dot. 


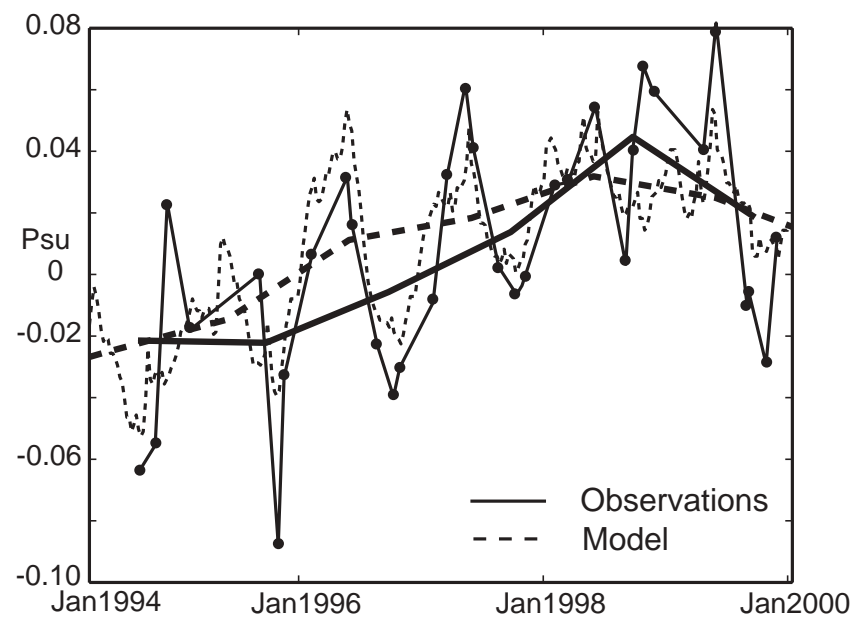

Figure 2. Horizontally averaged salinity deviations at $50 \mathrm{~m}$ depths along the Munken-Fair Isle section. The thicker lines show annual averages, and the individual measurements are indicated with the black dots.

pared to the simulated salinity treated in the same way (Fig. 2). The model explains the observed seasonality and the steep salinity increase during the 90 s. However, when the observed and simulated time series are considered for the Shetland Shelf region, the simulated salinity variability is much lower than the observed variability. This indicates that the simulated salinity is too diffusive or lacks details, but that integrated values are realistic. The simulated temperature, however, showed realistic variability both when considering a limited area on the Shetland Shelf and when looking at the integrated values. This observation is, among other processes, an indication of the weak atmosphere-ocean coupling for salinity (through evaporation minus precipitation and run-off) compared to temperature (through heat fluxes).

The observations from the Fair Isle-Munken section have been merged with observations from the Nolsoy-Flugga section further north in the FSC (Fig. 1) to produce a century long hydrography time-series [Turrell et al., 1993]. The averaged temperature field along the Fair Isle-Munken section is shown in the inset in Fig. 3b. The relatively warm pole-ward flowing Continental Shelf Current (CSC) is evident as the dark red colours on the Shetland Slope, and the equator-ward flowing cold overflow water is seen as the dark blue colours (extending from 500-600 $\mathrm{m}$ depth to the bottom).

The sub-region, shown with the white frame in the inset, covers the observations that are made inshore from the $300 \mathrm{~m}$ depth contour on the Shetland side of the channel. The hydrographic series provided by the Marine Laboratory in Aberdeen is calculated as a spatial average over this region and thus provides a good description of the hydrographical properties of the inflowing AW. A proper comparison of the observed and simulated salinity requires spatially integrated values from an area wider than the white frame, and since the observed salinity, in addition, is of less quality than temperature [Turrell et al., 1993], we focus on temperature in this study. When the simulated temperature is spatially averaged over the white frame area and compared to the observations, the temporal average is $9.73^{\circ} \mathrm{C}$ and $9.29^{\circ} \mathrm{C}$, respectively. The temperature anomalies shown in Fig. 3a are made by subtracting the average values from the actual time series.

In Fig. 3b, the observed data points in Fig. 3a have been binned into years and averaged, and the modelled data are picked out at the measurement times and averaged in the same
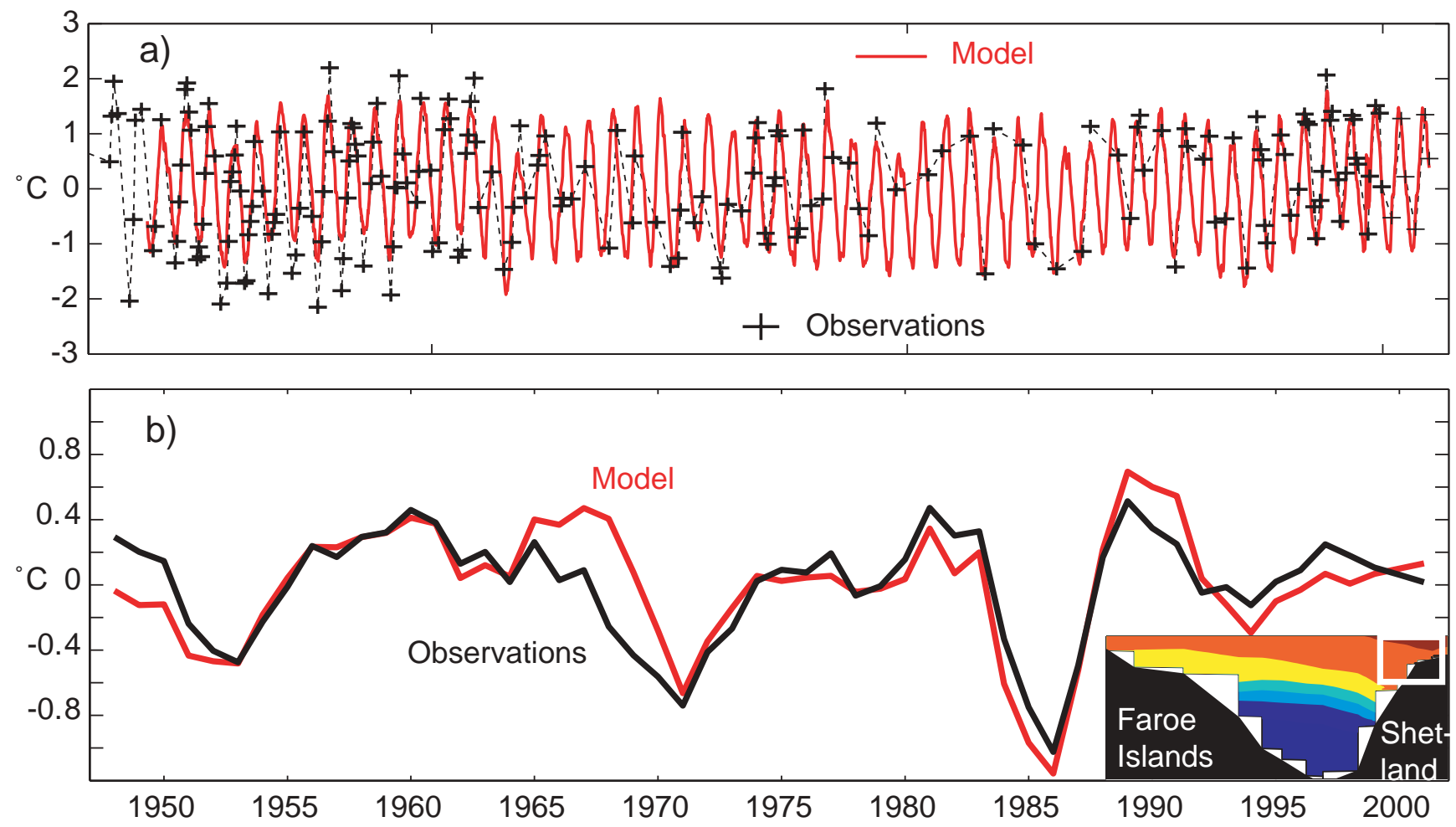

Figure 3. Temperature anomalies in the Faroe-Shetland Channel. Observed and simulated time series from the region shown within the white rectangle in the inset are presented (see text for details). a) The observations (plusses) and the weekly resolved simulated time series. b) Three year running averages (see text for averaging details). 
manner. In addition, a three-year running average has been applied for clarity. The presented curves are raw comparisons between the observed and simulated temperature anomalies, and should therefore not be interpreted as the true temperature variation from 1948 to present.

The correlation between the 195 raw temperature observations and the corresponding simulated temperature is 0.93 (before low-passing), and the correlation between annual averages drops to 0.63 . The very good raw data correlation is obviously much due to a correctly simulated annual cycle, but the annual averages are still significantly related. A comparison of annual averages is, however, not strictly meaningful since there is no straightforward way to remove the seasonal cycle before averaging as will be discussed in section 4.2. Nevertheless, this illustrates that the model is able to simulate the observed variability in the FSC. To further support this finding, the variability of the observed and simulated hydrographic conditions at the the Rockall Trough and the Svinøy section (see Fig. 1) has been conducted.
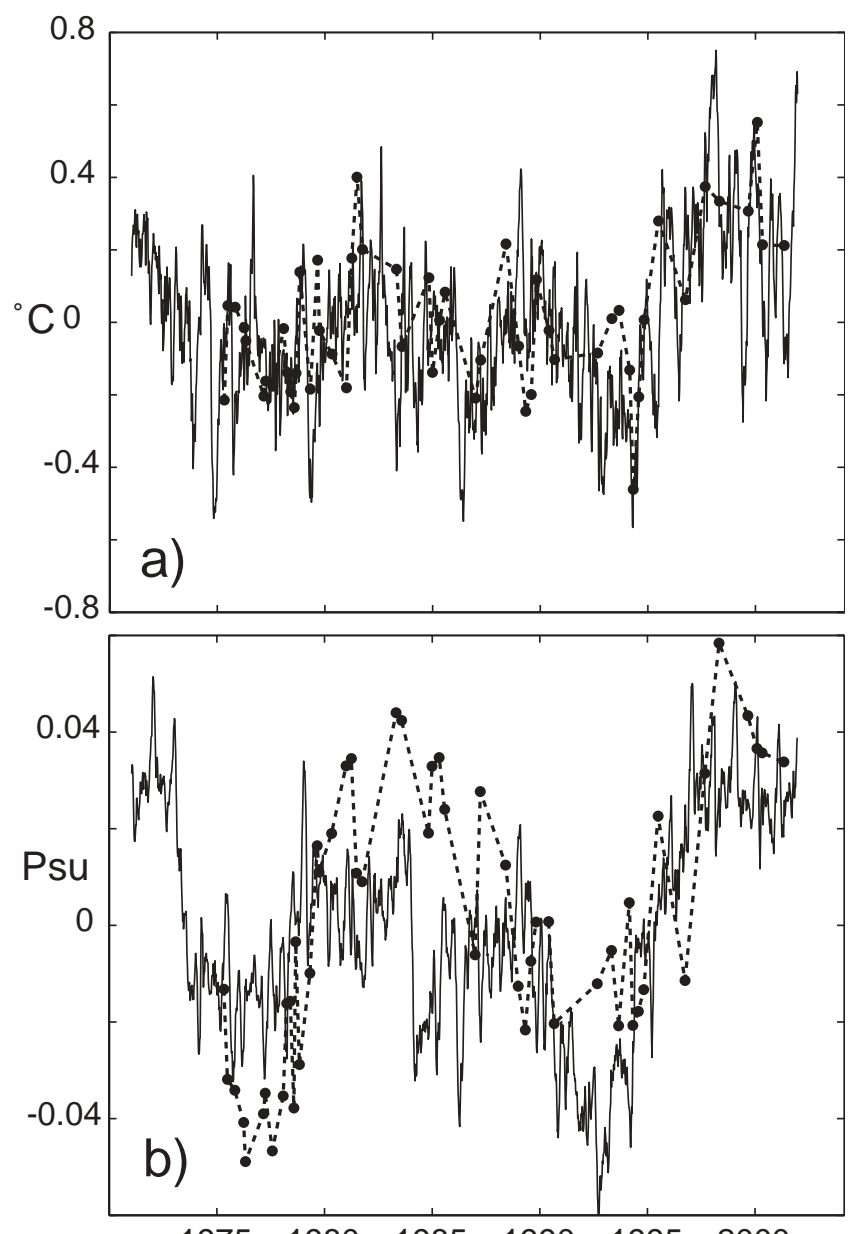

$\begin{array}{llllll}1975 & 1980 & 1985 & 1990 & 1995 & 2000\end{array}$

Figure 4 . The hydrography along the full Rockall Trough line averaged from surface to 800 meters depth: a) de-seasonalized temperature anomalies (observations: dots, simulations: curve) and b) deseasonalized salinity anomalies.

The Rockall Trough represents one pathway by which warm North Atlantic upper water reaches the Faroe-Shetland Channel. Temperature and salinity time series from a standard hydrographic section (the 'Ellet section', see Fig. 1) that crosses the northern Rockall Trough are available from ICES (www.ices.dk). Figure 4 shows the horizontally averaged, deseasonalized anomalies over the uppermost $800 \mathrm{~m}$ [Holliday et al., 2000] and the simulated time series processed in the similar way. The temporal averages of the presented simulated and observed time series are $8.97^{\circ} \mathrm{C}$ and $9.21^{\circ} \mathrm{C}$, respectively.

Furthermore, most of the AW inflow that passes through the discussed area in the FSC continues as the Shetland Current [Hansen and Østerhus, 2000] to the Svinøy section on the Norwegian Shelf (Fig. 1). Temperature measurements from high-quality CTD data along this section (supplied by the Institute of Marine Research, Bergen) have been spatially averaged over the region representing the AW inflow. Figure 5 shows the de-seasonalized observed and simulated time series. The temporal averages of the presented simulated and observed time series are both $7.4^{\circ} \mathrm{C}$.

In conclusion, the comparisons from the Rockall Trough and the Svinøy section show that the simulated long-term hydrographic conditions of the northward flowing AW are, indeed, realistic.

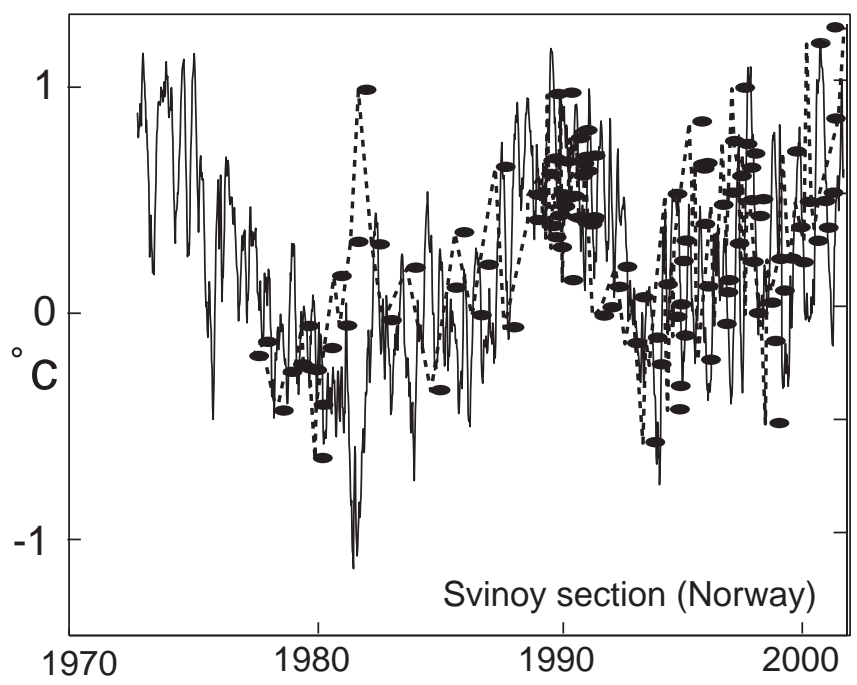

Figure 5. Temperature (de-seasonalized anomalies) from the Svinøy section averaged over an area embodying the northward flowing Atlantic water.

\section{SEASONALITY AND ALIASING}

\subsection{Coastal Temperature at Mykines}

Daily sea surface temperature (SST) measurements were made at Mykines (Fig. 1) during the period 1 January 1914 to 18 September 1969. The observation site is open to the Atlantic, the region has strong tidal currents (implying vigorous mixing), and there are no river outlets close to the site, and the series represents Faroe Shelf condition within $0.2^{\circ} \mathrm{C}$ [Hansen and Meincke, 1984].

The correlation between the raw Mykines series and the simulated temperature anomalies on the Faroe Shelf is 0.96 when monthly averages are compared and 0.75 when annual averages are considered. This shows that both the seasonal variations and interannual temperature variations on the Faroe Plateau are realistically simulated in an average sense. Observations and simulations are available concurrently from 1948 to 1969 and the number of samples each month during this period is shown as a stacked histogram in Figure 6b. Only the years 1949, 1950 and 1969 had entire months missing, and in 


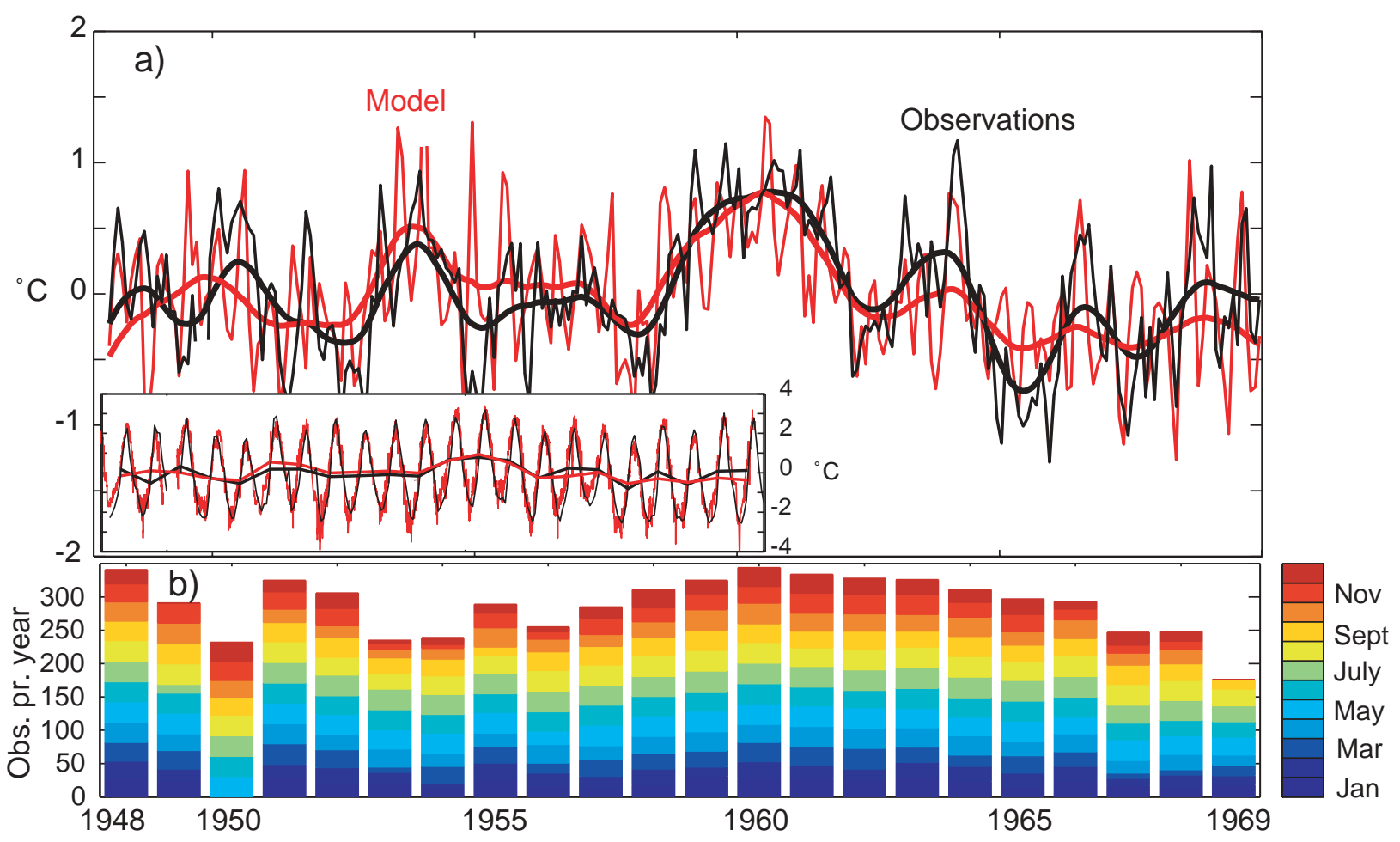

Figure 6. a) The coastal temperature (monthly averages and seasonal cycle removed) at Mykines (black) and the simulated temperature (seasonal cycle removed) on the Faroe Shelf (red). A 12-month running average is shown with the thicker lines. The inset shows the corresponding time series before de-seasonalizing. b) The sampling intensity during the period 1948-1969.

average there are 24 samples each month. With such a comprehensive data-coverage, annual averages are simply found by averaging every data point within each year, and by using the average seasonal cycle when isolated months are missing. By doing this, a fairly good correspondence is found between the two time series (Fig. 6a, inset). The temporal averages of the presented simulated and observed time series are $8.40{ }^{\circ} \mathrm{C}$ and $8.02^{\circ} \mathrm{C}$, respectively.

The temperature variations are clearly dominated by the seasonal cycle and aliasing would be a severe problem if only few samplings were available (see later). In analysing time series with a few observations each year, as is the common case for oceanic records, one has to remove the seasonal signal before averaging in order to remove possible bias caused by the few observations. Since the long-term variation is often small compared to the seasonal signal, care must be applied to the seasonal filtering. The fact that the seasonal amplitude and the timing of the annual temperature maximum in the ISR area are very variable [Hansen et al., 1994], complicates filtering of the annual cycle further. Therefore, filtering the seasonal cycle using an averaged cycle, could, for a year with an anomalous seasonal variation bring in an error to the filtered series. Even though this error is relatively small compared to the seasonal amplitude itself, it can be severe considering the slowly changing long-term averages.

The Mykines series is suitable to validate the simulated seasonal cycle. The seasonal cycle is symmetric and well described by a simple trigonometric function of the form $\mathrm{A} \cos (2 \pi \mathrm{t} / 365.25-\mathrm{p})$, where $\mathrm{A}\left({ }^{\circ} \mathrm{C}\right)$ is amplitude, $\mathrm{t}$ (day-number) is time and $\mathrm{p}(\mathrm{rad})$ is phase. A combination of various trigonometric functions, allowing for non-symmetric seasonal cycles, did not fit the actual seasonality significantly better than the simple cosine.

Seasonal filtering is performed by fitting the cosine to a time-
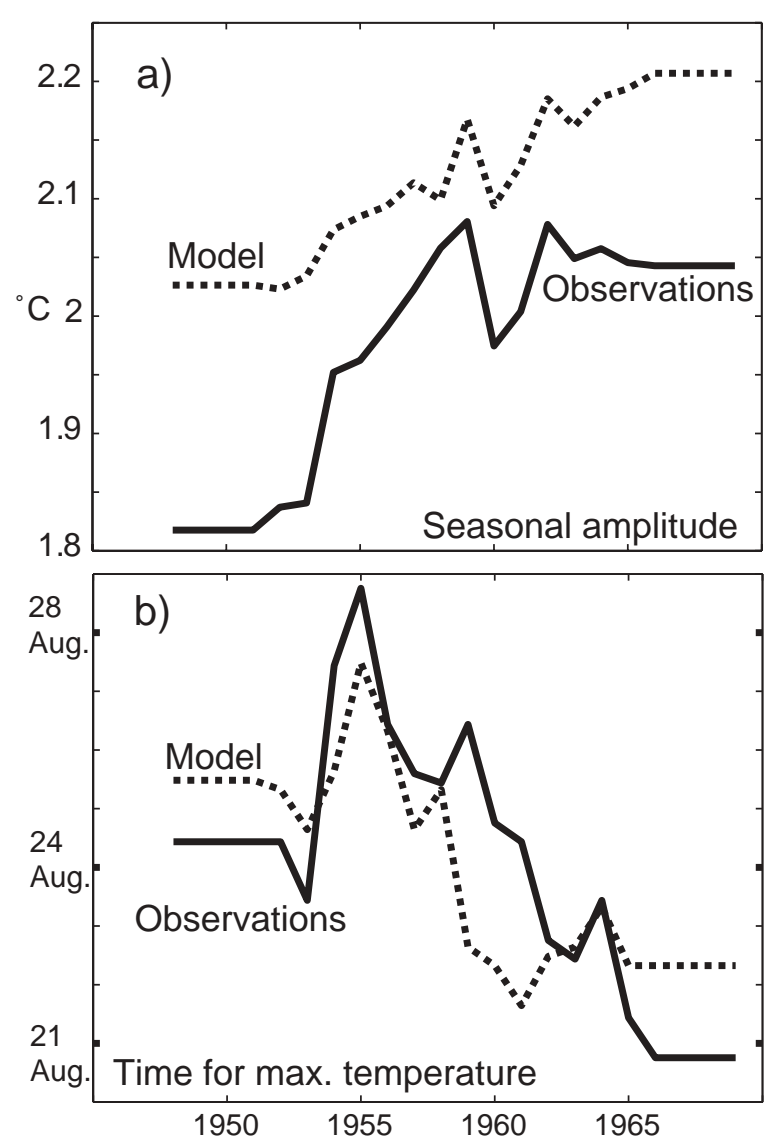

Figure 7. Change in the seasonal temperature variation on the Faroe Shelf: a) The observed (un-broken line) and simulated (broken line) strength in the seasonality, and b) the time, for each year, when the temperature maximum occurs. 


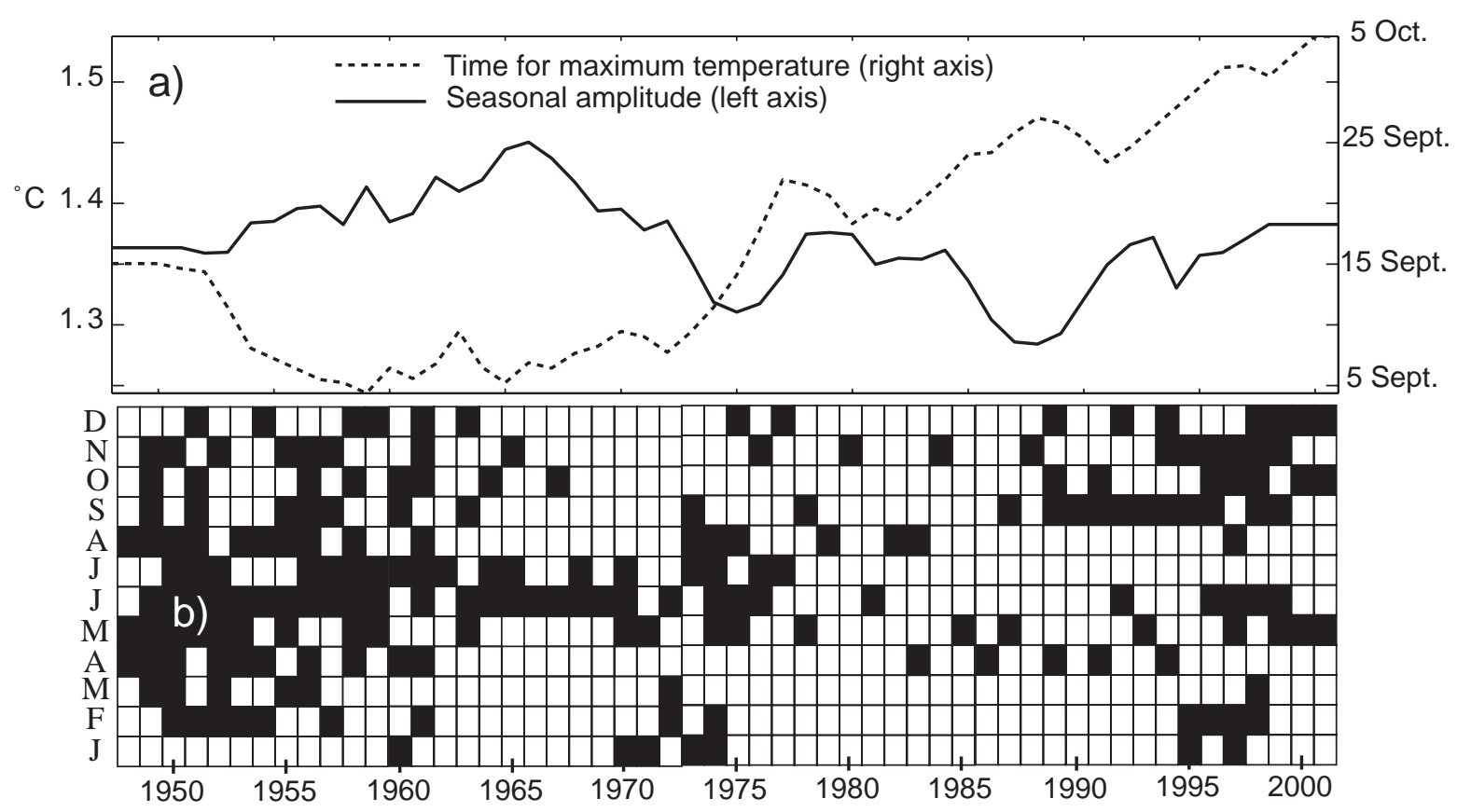

Figure 8. a) The simulated change in the seasonal temperature variation in the FSC. The un-broken curve (left y-axis) shows the amplitude of the seasonality and the broken curve (right y-axis) shows when, for each year, the temperature maximum occurs. b) Monthly overview over the employed measurement strategy in the FSC.

window of the series, and by subtracting the best-fit cosine from the year in the middle of the window. By letting the timewindow slide through the full series (Fig. 6a, inset) one obtains the de-seasonalized (filtered) series in Fig. 6a (note difference in scales). The amplitude and the phase from this analysis are found as time-dependent parameters. The narrower the window is, the better sudden changes in the seasonality are resolved, but a narrow window includes fewer values for the cosine-fitting and an error, caused by imperfect fitting, is brought in. It is found that a width of $8 \mathrm{yr}$ minimizes the errors caused by imperfect fitting and by the varying seasonality.

Values of the seasonal amplitude and phase, obtained from both observations and the model, are displayed in Figs. 7a and $7 \mathrm{~b}$. The figure shows that the simulated seasonal amplitude is larger than in reality by about $0.2{ }^{\circ} \mathrm{C}$, but that the changes in the two time series co-vary in time. The model obtains an increase in seasonality by nearly $0.2^{\circ} \mathrm{C}$ from 1948 to 1969 , while the observations show an increase of about $0.25^{\circ} \mathrm{C}$. The time for maximum temperature differs by less than two days between model and data, and both time series indicate that the maximum temperature is found 3-4 days earlier in the late 60s than in the late 40s. So, in addition to the long-term temperature variation and the average seasonal cycle, the model also predicts the seasonal modulation on the Faroe Plateau in a realistic way.

In the densely sampled Mykines series the 'true' annual averages and the 'true' seasonal cycle are known, and the need for a seasonal cycle with varying amplitude and phase can thus be tested. The temperature series is sub-sampled in different ways (monthly or more random) and the seasonal variations and the annual averages of these sub-sampled series are found using both a window-based, and full-series based deseasonalizing method. By comparing the results to the 'true' values an error estimate can be obtained for each method. The window-based method is found to perform better than the method, which is assuming an average seasonal cycle.

\subsection{The Faroe-Shetland Channel}

The observed FSC series in Fig. 3a has a character similar to the Mykines series with a dominating seasonal variation and a weaker decadal-scale variation. But, in contrast to the Mykines series, the sampling frequency is scattered throughout the measurement period (Fig. 8b), and aliasing will obviously be a severe problem.

No reliable information on a changing seasonality (amplitude and phase) can be obtained from available observations, but the temperature seasonality in the FSC is known to be very variable [Hansen et al., 1994]. This can even be seen by inspecting Fig. 3a, although the prominent decrease in the early 1960s could be due to a changed measurement strategy after 1960 [Turrell et al., 1993]. The error brought in by removing the observed seasonal cycle can therefore not be quantified with confidence and a model-data comparison of the true decadal-scale variations is thus not meaningful in itself. A model-data benchmarking is therefore limited to the point-wise comparison in Fig. 3.

Analyses shows that the modelled and observed seasonal cycles in the FSC are symmetrical and can be modelled with a simple cosine, just like was the case for the Mykines series. Fitting a cosine to the observed and simulated time series for the periods 1948 to 2001 gives the same amplitudes $\left(1.32^{\circ} \mathrm{C}\right)$, whereas phases differ by three days only and with maximum temperature in mid September. The seasonality is thus, in an average sense, simulated in a correct way. 

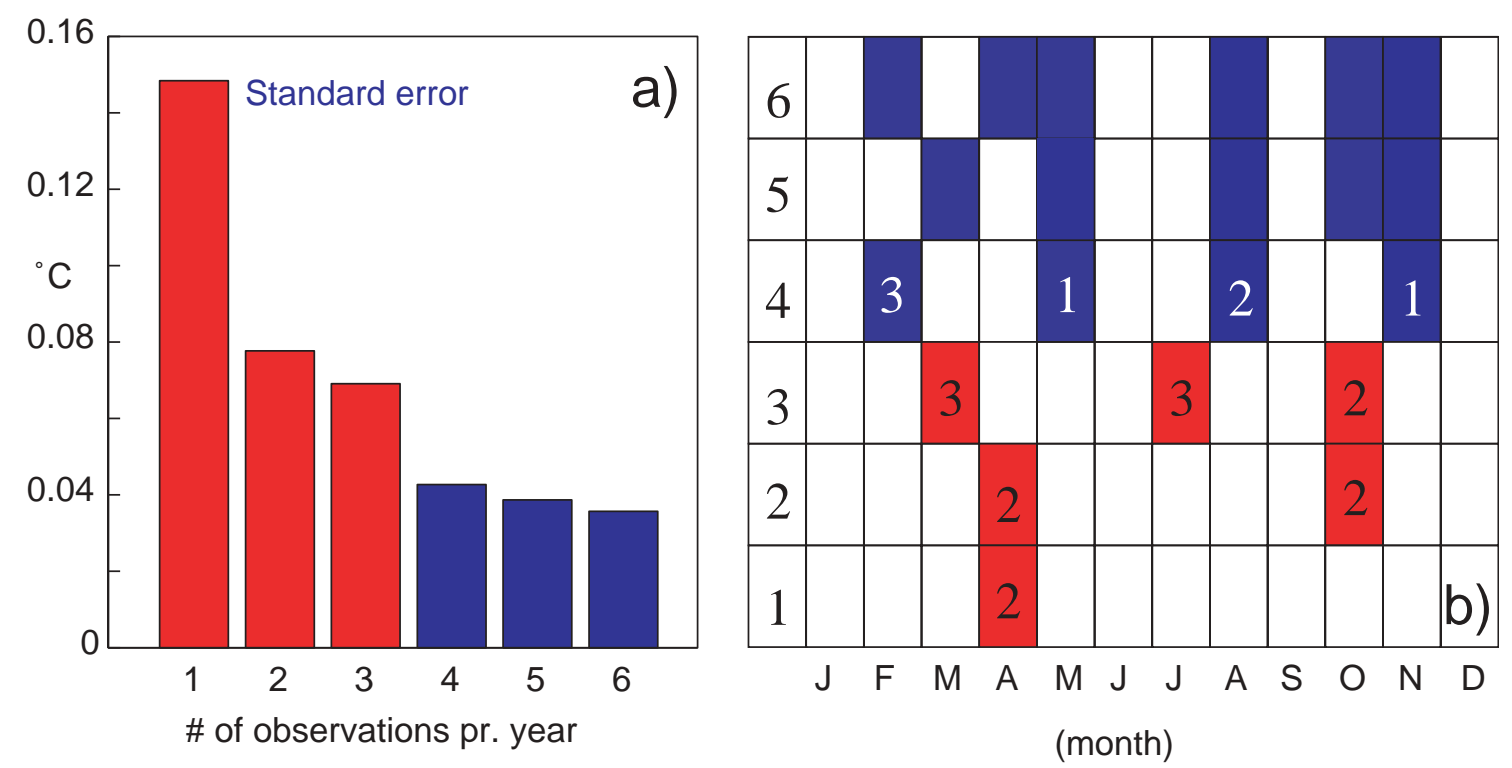

Figure 9. a) The error introduced by removing the seasonal variation as a function of available data points each year. Red bars show the error when less than four observations are taken each year. b) Optimal month (January to December) and week (indicated numbers) of observation, for 1 to 6 observations pr. year (left column). Months without numbers indicate the mid-month.

\section{POSSIBLE MODELAPPLICATIONS}

\subsection{Model-Based De-seasonalizing Error in the FSC}

The correlation coefficient between the time-series from Mykines and FSC is 0.75 , and the seasonal amplitude, the phase and the long-term variations of the Mykines series are well described by the model. It is therefore reasonable to assume that the model should explain some of the seasonal modulation in the FSC as well. With this assumption, one can use the model to quantify the error brought in when removing the observed seasonality in the FSC series.

The window-based de-seasonalizing method to the complete model time series from the FSC gives the values of the seasonal amplitude and phase as shown in Figure 8a. The figure shows that the simulated temperature amplitude varies more than $0.15^{\circ} \mathrm{C}$ during the integration period, and that the maximum temperature is found nearly one month later in year 2001 than in the 1960s. Note the changes around 1965, and that the amplitudes and the phases are inversely correlated.

The main causes for making errors when filtering the annual cycle are linked to the observational frequency, the timing of the observations (Fig. 8b), or changes in the annual temperature cycle (Fig. 8a). The 'true' annually averaged series is then based on the full (weekly-averaged) simulated time series. A sub-sampled model time series with the employed measurement strategy in Fig. 8b is generated; the seasonal variation based on the sub-sampled series is found and subtracted (and thereby errors are deliberately brought in), and the annual averages are calculated. During this procedure, the full-length time series (1948 to 2001) is used in the cosine fitting. The difference between the 'true' annual averaged and the one obtained after sub-sampling gives an estimate on the error brought in (see grey band in Figure 10).

\subsection{Model-Based De-seasonalizing Error in the FSC}

As a curiosity, the possibility to use the model as a guide for future monitoring is examined.

Sub-sampled model time series with one to six values each year are generated; the seasonal variation based on each subsampled series is found and subtracted, and the annual averages are calculated. This has been done for all combinations in each sub-sampled series, and the standard deviation from the 'true' annual average is calculated. The standard error found from the optimal way of placing the values throughout the year is provided in Fig. 9a. It follows that the gain in accuracy is particularly large for up to 4 values pr. year. The optimal measurement strategy when using four data-points each year, and based on 1948-2001 as the training period, is the third week in February, the first week in May, the second week in August and the first week in November (Fig. 9b), or about one month prior to the seasonal peaks and the zero-crossings of the annual temperature cycle. This is in accordance with the sampling rate of CTD data employed in the FSC and north of the Faroe Islands from the early nineties to present [Hansen et al., 2003; Turrell et al., 2003]. These monitoring programmes should thus be maintained and not reduced.

The standard de-seasonalizing error produced by the optimal measurement strategy of 4 cruises per year for the period 1948-2001 is about $0.04^{\circ} \mathrm{C}$ (Fig. 9a). For comparison, the standard error produced by the employed measurement strategy in the FSC over the same period is $0.17^{\circ} \mathrm{C}$, or larger than would be obtained with only one optimally located observation each year (Fig. 9). The large discrepancy is mainly caused by periods with few, non-optimal timed measurements during periods with a suddenly changed seasonality. Note that in the late 60 s only one to two measurements were made, mainly in JuneJuly, and that this was a period when the seasonal amplitude decreased sharply (Fig. 8). The checkerboard in Fig. 9b shows that it is not wise to monitor in June-July as this is near the zero-crossings of the annual temperature cycle. 


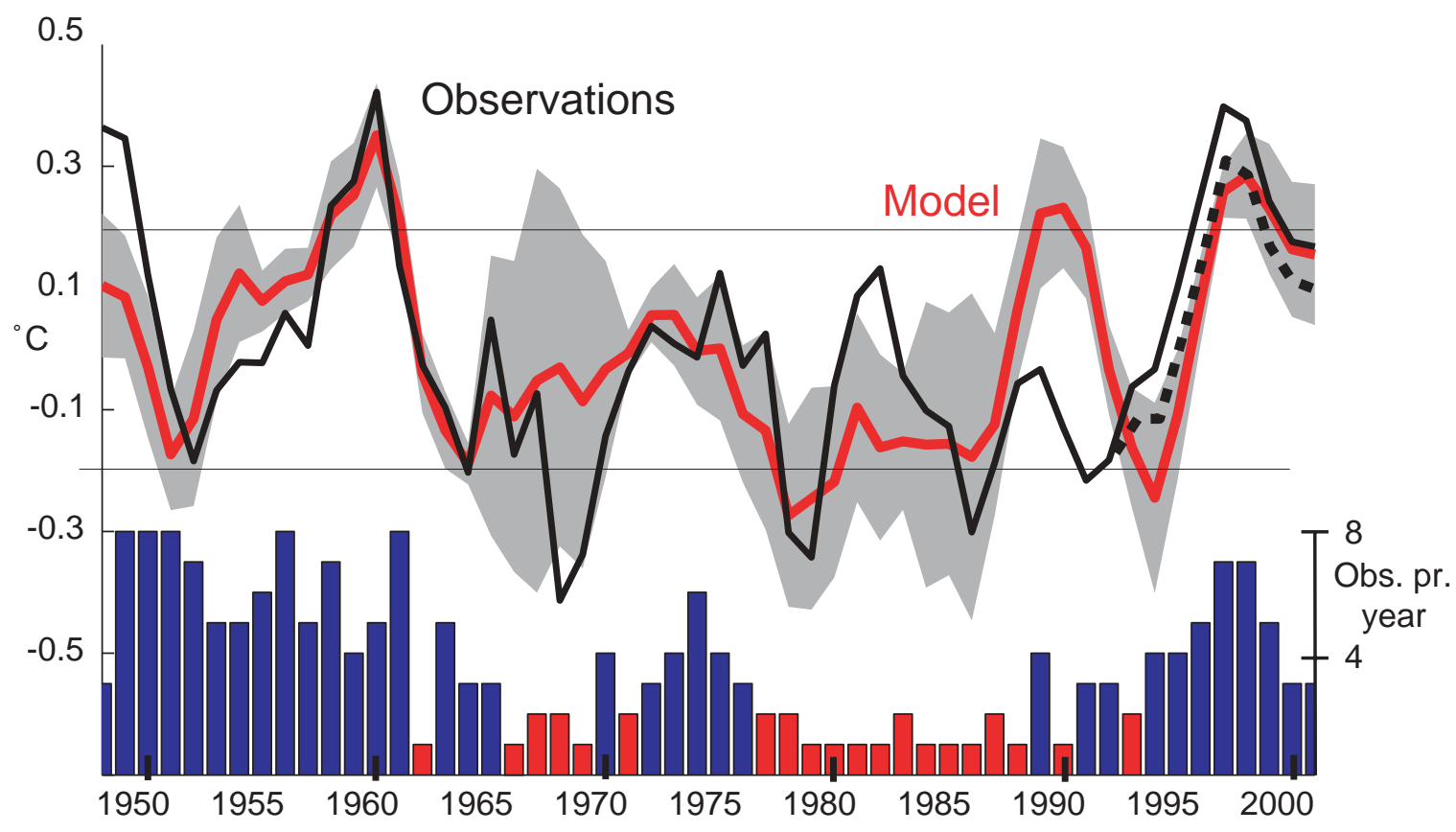

Figure 10. Observed temperature anomalies after removing the seasonal variation (three year running averages and de-trended), (black nondotted line). The weekly resolved simulated time series is shown in red. The grey zone illustrates the error introduced by de-seasonalizing as found by comparing sub-sampled and the full, simulated time series. The number of measurements made each year is shown with the histogram, years with less than four observations are shown in red. The dashed line shows the observations when only the CTD observations from 1994 to 2001 are considered.

\subsection{Homogenisation of the Observed Temperature Time Series}

If differences in the model-data comparison (Fig. 3) are small compared to the long-term variations and to the error brought in by filtering the seasonality, then the simulated time-series would have the potential to assist the observations during periods with sparse sampling. This is generally the case, except from the periods in the late 1960s and from 1989 to 1991 (Fig. 3b).

In Fig. 10, the full model time-series (weekly averaged values) is compared to the observed series, which has been deseasonalized with a cosine fitted to the full-length series. Only anomalies are shown, with the averaging as in Fig. 3b. The error from the process of removing the annual cycle, as described above, is illustrated with the grey band.

The discussed uncertain period in the late 60s shows up as a period with a broad grey band and large deviation between simulations and observations. The 80 s were surveyed once to twice a year and this is reflected in a model-data deviation and a rather broad error band. Only one cruise was made in 1990, but the previous and the subsequent year had a reasonable sampling (Fig. 8b) resulting in a narrow error-band, but still the model and the data disagree during this period. The observed series lies outside the error band throughout the 1990s, although good data are available for this period. The dashed line shows the result when analysing the high-quality CTD observations from 1994 to 2001 separately. This shows that a 'contamination' is introduced when analysing and making anomalies of the observed, full-length time-series as a whole, or that the high-quality CTD observations reduce the mismatch between the observed and simulated time series.

Sources for errors are many and unclear and the foundation for taking the analysis this far and for trusting the model more than observations are, admittedly, subjective. However, the presented analyses indicate the potential of using GCMs as interpolator for unevenly sampled ocean time series.

\section{DISCUSSION AND CONCLUSIONS}

The model compares well to the observed temperature variations on the Shetland side of the Faroe-Shetland Channel (FSC) at the irregular times when data are available (Fig. 3a,b). Support for the good model-data correspondence is found at the Rockall section ('Ellet line') and at the Svinøy section (Figs. 4 and 5). Furthermore, the applied model captures most of the seasonality, changes in the seasonality and the decadal temperature variations on the Faroe Shelf (Figs. 6 and 7).

Since the observed FSC time series is inhomogeneously sampled and with more energy on the seasonal cycle than on lower frequency variations, aliasing is a problem [Reverdin et al., 1994]. Reverdin er al. [1994] found that the use of available surface data can critically reduce the aliasing problem in the discussed FSC series. With support from the daily SST measurements from the Faroe Shelf and the fact that the model is able to simulate the observed surface temperatures on the Shetland Shelf practically perfectly (not shown), it should therefore be possible to further pursue the approach by Reverdin et al. [1994].

The variable seasonal cycle in the FSC [Hansen et al., 1994] enlarges the aliasing problem. Applying a time-window based de-seasonalizing procedure to the modelled series indicates that the seasonal modulation in amplitude and phase vary much throughout the integration period 1949-2001.

From telegraph cable measurements, Hansen et al. [1994] found that the seasonal temperature variation in the FSC almost turned off around 1910 and that this coincided with a temperature and salinity minima. They suggested that the 
changed balance between the Atlantic flow and the East Icelandic Current led to a disruption or reversion of the "normal" seasonal variation of the flow systems. The strongest modelpredicted modulation of the temperature seasonality in the FSC (Fig. 8a) happened from 1965 to 1977, which coincides with the Great Salinity Anomaly (GSA) of the 1970s, [Dickson et al., 1988]. The explanation for the changes in seasonality during the 1970s GSA is likely the same as the explanation for the 1910s GSA [Hansen and Kristiansen, 1994]. This indicates that the simulated seasonal modulation is physical and not only a numerical artefact.

By assuming that the simulated time series is exact, an estimate of the de-seasonalizing errors introduced by using a subsampled temperature time series is possible. The analysis indicates that it is not advisable to survey the hydrographic section less than four times a year if reliable decadal scale temperature variations are of interest.

This last point is clearly seen when comparing deseasonalized and averaged observations and the simulated lowfrequency temperature variations (cfr. Figs. 3 and 10). The observed and the simulated time series follow each other closely, and the error band from the de-seasonalizing is narrow, in case of four or more samples per year. For periods with poor sampling (red bars in Fig. 10), the error-band widens and the two time series diverge. This result calls for caution in interpreting the seemingly cold anomaly in the late 1960s and the seemingly warm anomaly in the early 1980s in Fig. 10 as real anomalies.

The Mykines series shows no cold anomaly in the late 1960s, and thereby supports the simulated time series. However, a cold anomaly is prominent north of Iceland [Malmberg and Valdimarsson, 2003] and at $400 \mathrm{~m}$ depth at the Ocean Weather Station "Mike" (OWSM) [Østerhus and Gammelsrød, 1999] in the late 1960s, indicating that a cold anomaly might have been an isolated feature in the Nordic Seas. The warm anomaly in the early 1980s is evident in the observed Rockall series and in the observed Svinøy series (Figs. 4 and 5). The model represents the anomaly at the Rockall section, but not at the Svinøy section. This anomaly is therefore probably real, but the model is seemingly not able to properly pass it properly through the FSC. The reason for the model-data misfit during the years 1989-1991 is unclear. The observed Rockall series shows no warm anomaly during this period, but both model and observations show this anomaly very clearly at the Svinøy section.

It should be mentioned that a potential problem in using the observational temperature series as presented here is the mix of the Fair Isle-Munken and the Nolsoy-Flugga sections. Analyses of the simulated temperature series from the two sections support fusion of the two lines, although the short overlap between the two observed temperature series [Ellet and Turrell, 1992] makes the fusion statistically weak.

Finally, an ultimate description of the ocean dynamics and thermodynamics will be based on data assimilation systems where observations and simulated fields are merged in an optimal way. Unfortunately, the sparse temporal-spatial sampling of the ocean, in combination with the small length scales found in the region, makes such an approach difficult. It is therefore encouraging that hind-cast simulations like the one presented here show realistic behaviour in several aspects, illustrating the potential of hind-cast simulations to expand observed time series, and to evaluate the highly observational-demanding and complex coupled atmosphere-sea ice-ocean climate models.

\section{REFERENCES}

Anderson, L. G., Drange, H., Chierichi, M., Fransson, A., Johannessen, T., Skjelvan, I., and Rey, F. (2000), Seasonal and annual variability in the upper Greenland Sea based on measurements and a box model, Tellus, 52B, 1013-1020.

Beaugrand, G. and Reid, P. C. (2003), Long-term changes in phytoplankton, zooplankton, and salmon linked to climate, Glob.Change Biol., 9, 801-817.

Belkin, I. M., Levitus, S., Antonov, J., and Malmberg, S. Aa. (1998), "Great Salinity Anomalies" in the North Atlantic, Progress in Oceanography, 41, 1-68.

Bentsen, M., Drange, H., Furevik, T., and Zhou, T. (2004), Simulated variability of the Atlantic meridional overturning circulation, Clim.Dynam., In Press.,

Bleck, R., Rooth, C., Hu, C., and Smith, L. T. (1992), Salinity-driven thermohaline transients in a wind- and thermohaline-forced isopycnic coordinate model of the North Atlantic, Journal of Physical Oceanography, 22, 1486-1515.

Dickson, R. R. and Brown, J. (1994), The production of North Atlantic Deep Water: Sources, rates, and pathways, Journal of Geophysical Research 99.

Dickson, R. R., Meincke, J., Malmberg, S. Aa., and Lee, A. J. (1988), The "Great Salinity Anomaly" in the Northern North Atlantic 19681982, Progress in Oceanography, 20, 103-151.

Ellet, D. J. and Turrell, W. R. (1992), Increased salinity levels in the NE Atlantic, ICES CM 1992/C:20.

Furevik, T. (2001), Annual and interannual variability of Atlantic water temperatures in the Norwegian and Barents Seas: 1980-1996, Deep Sea Research, 48, 383-404.

Furevik, T., Bentsen, M., Drange, H., Johannessen, J. A., and Korablev, A. (2002), Temporal and spatial variability of the sea surface salinity in the Nordic Seas, Journal of Geophysical Research 107.

Hansen, B., Joensen, H. P., and Michelsen, V. E. (1994), Bottom temperature between Iceland and Shetland 1906-1962 measured in telegraph cables, ICES CM 1994/S:5.

Hansen, B. and Kristiansen, R. (1994), Long-term changes in the Atlantic water flowing past the Faroe Islands, ICES CM 1999.

Hansen, B. and Meincke, J. (1984), Long-term coastal sea surface temperature observations at the Faroe Islands, Rapports et ProcèsVerbaux des Réuinons du Conseil International pour l'Exploration de la Mer 185.

Hansen, B. and Østerhus, S. (2000), North Atlantic-Nordic Seas Exchanges, Progress in Oceanography 45.

Hansen, B., Østerhus, S., Hátún, H., Kristiansen, R., and Larsen, K. M. H. (2003), The Iceland-Faroe inflow of Atlantic water to the Nordic Seas, Progress in Oceanography, 54, 443-474.

Helland-Hansen, B. and Nansen, F. (1909), The Norwegian Sea, Fiskeridirektoratets Skrifter Serie Havunders $\varnothing$ kelser, 2, 1-390.

Holliday, N. P., Pollard, R. T., Read, J. F., and Leach, H. (2000), Water mass properties and fluxes in the Rockall Trough, 19751998, Deep Sea Research 47.

Kistler, R., Collins, W., Saha, S., White, G., Wollen, J., Kalnay, E., Chelliah, M., Ebisuzaki, W., Kanamitsu, M., Kousky, V., Van den Dool, H. Jenne R., and Fiorini, M. (2001), The NCEP-NCAR 50Year Reanalysis, Monthly Means, CD-ROM and Documentation Bulletin of the American Meteorological Society, 82, 247-268.

Kristmannsson, S. (2001), Flow of Atlantic Water into the Northern Icelandic Shelf Area, 1985-1989, ICES cooperative Research Report 225.

Levitus, S. and Boyer, T. P. (1994), World Ocean Atlas 1994 Volume 
4: Temperature. NOAA Atlas NESDIS 4.

Levitus, S., Burgett, R., and Boyer, T. P. (1994), World Ocean Atlas 1994 Volume 3: Salinity. NOAA Atlas NESDIS 3.

Malmberg, S. Aa. and Valdimarsson, H. (2003), Hydrographic conditions in Icelandic waters, 1990-1999, 219, 1-453.

Miyakoda, K. and Sirutis, J. (1986), Manual of E-physics, 72pp, Geophysical Fluid Dynamics Laboratory, Princeton University, Princeton, New Jersey.

Nilsen, J. E., Gao, Y., Drange, H., Furevik, T., and Bentsen, M. (2003), Simulated North Atlantic-Nordic Seas water mass exchanges in an isopycnic coordinate OGCM, Geophysical Research Letters,

Østerhus, S. and Gammelsrød, T (1999), The abyss of the Nordic Seas is warming, Journal of Climate 12.

Reverdin, G., Cayan, D., Dooley, H. D., Ellet, D. J., Levitus, S., Penhoat, Y. D., and Dessier, A. (1994), Surface salinity of the North Atlantic: Can we reconstruct its fluctuations over the last one hundred years?, Progress in Oceanography 33.

Sakshaug, E., Bjørge, B., Gulliksen, B., Loeng, H., and Mehlum, F. (1994), Structure, biomass distribution, and energetics of the pelagic ecosystem in the Barents Sea: A synopsis, Polar Biol., 14, 405-411.

Turrell, W. R., Devonshire, E., Payne, R., and Slesser, G. (1993), Analysis of the historic time-series obtained in the Faroe-Shetland Channel, ICES CM 1993/C:29.

Turrell, W. R., Hansen, B., Hughes, S., and Østerhus, S. (2003), Hydrographic variability during the decade of the 1990s in the Northeast Atlantic and southern Norwegian Sea, Marine Science Symposia, 219, 111-120.

Annebritt Sandøe: Nansen Environmental and Remote Sensing Centre, Edv. Griegsv. 3A, 5059 Bergen, Norway.

annebrit@nersc.no

Helge Drange: 1) Nansen Environmental and Remote Sensing Centre, Edv. Griegsv. 3A, 5059 Bergen, Norway. 2) Geophysical Institute, University of Bergen, Allegaten 70, 5007 Bergen,

Norway. 3) Bjerknes Centre for Climate Research, Allgaten 55, 5007 Bergen, Norway. 4) Nansen-Zhu International Research

Centre, Beijing 100029, China. helge.drange@nersc.no

Hjálmar Hátún: Faroese Fisheries Laboratory, Nóatún 1, FO-

110, Faroe Islands. hjalmarh@frs.fo

Mats Bentse: 1) Nansen Environmental and Remote Sensing

Centre, Edv. Griegsv. 3A, 5059 Bergen, Norway. 2) Bjerknes

Centre for Climate Research, Allgaten 55, 5007 Bergen, Norway.

mats.bentsen@nersc.no 
